\title{
Valores culturales en la publicidad exterior: entre la intención comunicativa y la apropiación del mensaje
}

\author{
Beatriz Eugenia Quiceno-Castañeda** \\ Carlos Andrés Arango-Lopera*
}

Recibido: 20 de febrero de 2012 Aprobado: 27 de marzo de 2012

\begin{abstract}
Resumen
El presente artículo indaga por las relaciones entre publicidad exterior y consumo, desde un análisis que combina técnicas cuantitativas y cualitativas. Parte de asumir que si bien existe consenso en que la publicidad influye en la cultura, es necesario propiciar acercamientos más directos al fenómeno publicitario, para reconocer en casos particulares cómo se produce esta interacción. Para indagar en la relación publicidad-cultura, este trabajo realiza una doble delimitación: ante la gran variedad de formatos, estrategias y tácticas publicitarias que pudieran investigarse, este trabajo se enfoca en la publicidad exterior ubicada en una zona específica de la ciudad de Medellín, lo cual permite concentrar la mirada en un entorno determinado, con unas características socioeconómicas concretas. De igual manera, de todos los fenómenos de cultura que pudieran analizarse, se ha elegido el de los valores culturales secundarios, para reconocer cómo la retórica publicitaria retoma tópicos admitidos como válidos por un grupo social, y los usa para convertirlos en vehículos argumentales de sus mensajes publicitarios. Así, este proyecto concentra la mirada en la forma como los mensajes de las piezas publicitarias interpelan (o no) el conjunto de creencias sobre el mundo y sobre sí mismos que se consignan en los valores culturales que integran el mundo social de los ciudadanos.
\end{abstract}

Palabras clave: publicidad, valores culturales secundarios, cultura, jóvenes, categorías de consumo.

* Este artículo presenta resultados de la investigación "Valores culturales secundarios presentes en la publicidad exterior de la Zona Rosa de Medellín entre la Calle 10 (Éxito de El Poblado hasta centro comercial Vizcaya) y la Avenida El Poblado (entre San Diego y la Aguacatala)", financiada por la Vicerrectoría de Investigaciones de la Universidad de Medellín. Investigadora principal, profesora Beatriz Eugenia Quiceno Castañeda; co-investigador, Carlos Andrés Arango Lopera. Asesoría metodológica, antropóloga Lina María Pineda Martínez. Auxiliares de investigación: Fabián Andrés Correa, Manuela Vélez y David Zapata Madrid.

** Comunicadora Social-Periodista Universidad Autónoma de Occidente Cali. Especialista en Comunicación Organizacional Universidad Autónoma de Occidente Cali. Magíster en Acción Humanitaria Internacional Real Universidad de Groningen Países Bajos. Docente-investigadora de la Facultad de Comunicación de la Universidad de Medellín, adscrita al programa de Comunicación Gráfica Publicitaria. Correo electrónico: bquiceno@udem.edu.co.

*** Profesional en Comunicación y Relaciones Corporativas, Universidad de Medellín. Especialista en Ética y magíster en Filosofía de la Universidad Pontificia Bolivariana. Docente-investigador de la Facultad de Comunicación de la Universidad de Medellín, adscrito al programa Comunicación Gráfica Publicitaria. Integrante del grupo de investigación COP (Comunicación, Organización y Política), donde investiga en la línea Comunicación Publicitaria. Sus áreas de interés son música, consumo y cine, sobre los cuales ha publicado artículos en periódicos y revistas dentro y fuera del país. Correo electrónico: caarango@udem.edu.co. 


\title{
Cultural Values in Foreign Publicity: Between Communicative Intention and the Appropriation of the Message
}

\begin{abstract}
This article looks for relations between foreign publicity and consumption, from an analysis which combines qualitative and quantitative techniques. It goes from assuming that if it is true that publicity influences culture, it is necessary to make more direct approaches to the publicity phenomenon possible, in order to find how this interaction is produced, in special cases. In order to search in the publicityculture relationship, this article shows a double delimitation: before the large variety of forms, strategies, and advertising tactics which may be investigated, this article focuses on the foreign publicity placed on a specific place in Medellin city, which allows concentrating the observation on a determined environment with concrete socio economic characteristics. Likewise, from all cultural phenomena to be analyzed, the secondary values have been selected in order to recognize how publicity rhetoric retakes topics admitted as valid by a social group and uses them to convert them in argumentative articles of their publicity messages. This project focuses on the way how publicity messages question or not question the group of beliefs about the works and the man himself which fall on cultural values which integrate the social world of citizens.
\end{abstract}

Key words: advertising, secondary cultural values, culture, youth, consumer categories. 


\section{INTRODUCCIÓN}

La publicidad es el dispositivo discursivo empleado por la economía de mercado para acelerar el subsistema de consumo (Aprile, 2000). En este modelo económico basado en la oferta y la demanda, el consumo es la plataforma que le da dinamismo al sistema económico, y sin el cual no podría existir. Por esa razón, la publicidad es susceptible de muchas miradas, además de la propiamente económica; así, debido al auge de mensajes publicitarios a que las personas están expuestas en su día a día, desde diversos ámbitos de la vida social y académica se han cuestionado seriamente los efectos sociales de la publicidad masiva.

De tal manera que lo publicitario se encuentra en el centro de interés de muchos actores sociales: los anunciantes desean saber qué publicidad producir para generar más impactos en sus ventas; las ligas de consumidores propenden por una publicidad no engañosa; algunos sectores de las ONG ven la publicidad como amenaza de la condición de género y etnia; los urbanistas suelen ver en la publicidad (particularmente la exterior) un factor de contaminación visual y auditiva; los empresarios del negocio publicitario buscan ofrecerles las mejores estrategias a sus clientes.

Con todo, el evidente impacto de la publicidad en los grupos sociales viene a implicar efectos más allá de las compras efectivas que se realicen, pues tanto lo que esta anuncia como la manera de hacerlo media imaginarios, discursos y estilos de vida que se vuelven del interés social, y a partir de los cuales las personas viven el mundo y se entienden en él (Rincón, 1998; Marina, 2007). Por esta razón no es adecuado pensar la publicidad en una única dirección (de los anunciantes a los consumidores), pues en la otra dirección también se producen sentidos (de los consumidores a los anunciantes, las marcas y los productos). Esta óptica se obtiene cuando el acto publicitario se asume desde la comunicación (Aprile, 2000), con lo cual queda claro que la suerte de los mensajes publicitarios está relacionada con el capital simbólico de los perceptores (Bourdieu, 2010); en otras palabras, que el mensaje publicitario más que recibido pasivamente es co-construido por las audiencias ${ }^{1}$.

En ese sentido, y teniendo en cuenta el alto impacto de la publicidad exterior, se hace necesario promover acercamientos que indaguen desde lo cultural la relación entre publicidad y consumidores, para reconocer -de un lado- cómo la publicidad aprovecha el conocimiento de los valores culturales de los consumidores y -del otro- cómo ellos apropian esos mensajes y los incorporan en su vida cotidiana.

Particularmente, el tema de los valores recoge una larga tradición en la historia del pensamiento de Occidente. Desde las primeras discusiones de los filósofos griegos, se habló de la virtud, el antecedente más remoto del concepto más contemporáneo de valor. En la idea de ciudad que promovió Aristóteles en su Política, la razón por la cual los ciudadanos decidían vivir juntos era, fundamentalmente, evitar el miedo que produce el estado de naturaleza. Vivir juntos era una manera de protegerse. Y la cuota con la que cada ciudadano respondía a los beneficios de estar juntos era la virtud. Esta, en escencia, se refiere a la excelencia en el cumplimiento de la naturaleza. El ejemplo clásico era el cuchillo: un buen cuchillo es aquel que corta bien, es decir, el que cumple

1 En este sentido, la escuela latinoamericana de la comunicación ha marcado un referente mundial. Desde la obra de teóricos como Jesús Martín-Barbero (1995), Guillermo Orozco (2001) y Néstor García (1995), ha ganado fuerza una noción decisiva: las formas culturales desde las cuales los contenidos mediáticos son recepcionados influye en la interpretación de los mismos. Por tanto, hay que centrar la mirada en el circuito de la recepción como un circuito activo de apropiación del mensaje y no como una instancia pasiva de asimilación de contenidos. Así, el interés debe estar no tanto (o por lo menos no solo) en la influencia del medio sobre la audiencia, sino sobre las estrategias que las personas usan para apropiarse de los mensajes que los medios proponen. 
satisfactoriamente eso para lo cual fue creado. En el caso de los seres humanos, cuya razón de vivir no está prefijada, la virtud apela a la excelencia en el cumplimiento de la naturaleza humana; y la naturaleza humana lleva a ser más humano. Quizá por esta razón comúnmente se asocia virtud a las construcciones morales que luego aprovecharon este discurso, en especial la moral católica. Sin embargo, si bien durante gran parte de la historia se asimiló la virtud con la virtud católica, la ruptura que produce Nietzsche es radical: en su Genealogía de la moral, el filósofo alemán destruyó la idea del bien en sí: no hay algo que en sí mismo se considere bueno; las valoraciones de bien y mal surgen en un juego histórico de poder: lo que se califica de bueno es lo que ayuda a mantener esa distancia entre los poderosos y los miserables.

Esta ruptura abrió la puerta para que se ampliara la noción de valor. Ya no se trata de una concepción unívoca ni referida únicamente a lo moral (Montoya, 1964). Sobre esta ruptura, algunos antropólogos culturales supieron señalar mediante sus investigaciones empíricas, que cada cultura construía diversos caminos para descodificar el mundo en acciones positivas o negativas. Esto lo comprobaron a través de múltiples relatos, rituales, mitos y regulaciones sociales. De tal suerte que a lo largo de muchos grupos sociales encontraron figuras heroicas que servían para narrar el transcurso del caos al orden. Estas narrativas han ido dejando unas huellas arquetípicas que, según lo comprobó Campbell (1953) son universales. Pero mientras los héroes clásicos existieron en los relatos epopéyicos y trágicos, en la Contemporaneidad los relatos tienen otros formatos, aunque la misma estructura. Así, la publicidad deviene hoy (Marina, 2007) una narrativa que configura las relaciones entre lo que es deseable y lo que no. De ahí que la retórica publicitaria es uno de los instrumentos discursivos de mayor impacto en una sociedad, razón por la cual los valores y valoraciones del mundo que se promueven desde allí resultan de vital importancia para comprender en qué mundo vivimos.
Dichas ideas son el contexto de la pregunta orientadora de este trabajo ¿Cómo los valores culturales secundarios presentes en la publicidad exterior ubicada en la avenida El Poblado entre San Diego y la Aguacatala y la calle 10 entre el Centro Comercial Monterrey y el centro comercial Vizcaya influyen en la manera como los consumidores se apropian del mensaje? En Medellín, esta zona es reconocida como de un alto valor aspiracional, porque representa a la clase con mayor poder adquisitivo. En ella, hay dos sectores ampliamente asociados a un estilo de vida de clase social privilegiada: la Milla de Oro, así como la calle 10, la cual sirve de acceso en sentido occidente-oriente a la Zona Rosa, lugar donde la oferta de entretenimiento (rumba) es bastante concentrada. Asimismo, la múltiple presencia de oficinas hace que el lugar tenga una diversidad en materia de publicidad bastante amplia, y una carga simbólica social muy alta porque habitan personas con mucho poder adquisitivo, en tanto que hacia allí mismo se dirigen personas de clases sociales media y baja en busca del reconocimiento social que en el imaginario colectivo representa la zona.

Para dar respuesta a la pregunta de investigación, se desarrolló durante los años 2010-2011 la investigación que da origen a este artículo y cuyos objetivos apuntaron a analizar cómo los valores culturales secundarios presentes en la publicidad exterior afectaban la apropiación del mensaje por parte de los consumidores.

\section{Materiales y métodos}

El presente estudio se desarrolló en la ciudad de Medellín, Colombia, la segunda ciudad más importante de este país, con una población esti mada en 2.343.049 habitantes (DANE, 2011). Es el segundo centro industrial del país y su renglón de textil y moda representa el 53\% del empleo industrial de la región (Alcaldía de Medellín, 2011). Medellín es una ciudad reconocida y promocionada por el turismo de salud, los eventos de moda 
y las compras (Guía turística de Medellín, 2011). En esta ciudad, marcada por un deseo mimético (Girard, 2008) $)^{2}$, la industria de la moda, los eventos y el comercio producen una gran cantidad de símbolos y retóricas, cuyo análisis requiere un tratamiento metodológico especial, pues debe atender dos frentes: las piezas publicitarias y las estrategias de aproximación, lectura e interpretación que de ellas realizan los ciudadanos. La orientación metodológica estuvo guiada por los preceptos de la perspectiva crítico-racional, que García y Berganza (2005) definen como una orientación propuesta de "... recuperar, para los fines humanos, para los valores, su lugar en la ciencia" tal como lo pretendía la Escuela Crítica $(2005,30)$.

Por lo anterior, la investigación se realizó en dos fases. En primer lugar, se definió un área específica de estudio en la ciudad de Medellín, El Poblado, un sector donde viven las personas de mayor poder adquisitivo de la ciudad y donde se ubica la zona de comercio y ocio más costosa dentro de la oferta de estos sectores en Medellín. Para la escogencia de las piezas publicitarias se hizo un inventario de las vallas y eucoles ubicados en el sector; esta se desarrolló en cuatro salidas donde se hizo registro fotográfico de las piezas, a partir de las cuales se levantó una cartografía de la publicidad ubicada en vallas y anuncios en los paraderos de los buses, conocidos como eucoles. Las salidas de campo se hicieron en tres momentos que son de gran importancia para el sector comercial: Día de Amor y Amistad, Día de los Niños e inicio de la temporada navideña.

Una vez hecho el registro fotográfico, se elaboraron las fichas de análisis de imagen donde se analizó el código publicitario desde el nivel tópico, icónico, iconográfico y tipológico de cada una de las piezas registradas fotográficamente. Para con-

2 Girard se refiere a un deseo de ser visto de determinada manera, siguiendo ideales estéticos construidos por el grupo social. struir dicha ficha se tomó como base lo expuesto por Umberto Eco (Eco, 1986) en su análisis sobre el mensaje publicitario donde se plantea que la publicidad está fundada sobre la premisa de que un anuncio puede atraer más la atención en la medida en que trasgrede las normas comunicativas usuales, lo que puede producir un trastorno en las expectativas retóricas de quien lo recibe. A partir de las fichas de análisis de imagen y las fotografías, se eligieron las piezas publicitarias que debían ser utilizadas para los grupos de discusión. Se eligieron por imágenes y/o textos que contenían implícita o explícitamente valores secundarios o que, en opinión del grupo investigador, podrían facilitar la discusión de dichos valores. De esta elección se definieron 6 categorías de clasificación y posterior análisis para las piezas publicitarias así: vestuario, cuerpo, bebidas, telefonía, cívica y vivienda.

La segunda técnica que se utilizó en esta investigación fueron los grupos de discusión, cuyo objetivo es mostrar tanto a los académicos como a los científicos, la importancia de estudiar fenómenos sociales desde lo estructural y lo dialéctico, generando en el individuo la posibilidad de expresar su capacidad reflexiva, y ser protagonista y operador de su propio discurso (Chávez, 2007).

A esta técnica se le introdujo una variante relacionada con los detonadores que son aquellos que movilizan la discusión dentro del grupo. Si bien Chávez (2007) sugiere que los detonadores no son preguntas sino eventos que incitan a hablar al grupo, para este caso las imágenes seleccionadas operaron como los detonantes. Estas sirvieron a la persona que guio la sesión, pues desde ellas lanzó preguntas iniciales con el fin de orientar de una manera más adecuada la discusión de los sujetos frente a la publicidad.

Igualmente, si bien en los grupos de discusión no se hacen preguntas directas a los entrevistados, sino que se lanzan enunciados abiertos para alentar la discusión (Chávez, 2007), en esta inves- 
tigación las preguntas hicieron parte de la técnica como una forma de romper el hielo e iniciar la discusión en torno a la publicidad exterior, dada la sensibilidad y la timidez inicial que mostraron los miembros de los grupos a categorías tales como cuerpo, bebidas y vestuario.

Teniendo en cuenta que las piezas publicitarias seleccionadas están dirigidas a personas entre 18 y 35 años, los integrantes de los grupos de discusión se seleccionaron entre personas que frecuentan la zona elegida para el estudio en calidad de transeúntes y/o visitantes, estudiantes universitarios hombres y mujeres que cumplían con el rango de edad anteriormente mencionado.

Según la investigación "Caracterización de los jóvenes de la ciudad de Medellín" los jóvenes de hoy son poco dados a adherir a una religión específica y esto lo han ido remplazando por la apropiación de una serie de valores éticos por los cuales se rigen en sus relaciones con los otros (Pérez \& Londoño, 1997). Dicha investigación permitió una mirada más acertada en cuanto al tipo de análisis que se quería hacer y cómo los hallazgos de esta investigación podrían relacionarse con esa nueva mirada del joven de hoy con relación a sus valores.

Se realizaron dos grupos de discusión conducidos por una persona experta en enfoque cultural de mercadeo. Para la realización de estos grupos se tuvieron varias reuniones previas, donde, de acuerdo con las categorías de publicidad que se habían elegido, se definió el campo semántico, es decir el terreno léxico desde el cual se organizaba temáticamente cada sesión (Chávez, 2007) a partir de una serie de preguntas que se harían cada que se discutieran las categorías. Esta decisión obedece a que los campos semánticos deben ser transversales e independientes de las categorías analizadas, con el fin de facilitar la comparación del comportamiento discursivo de los sujetos a través de las categorías.
Este campo semántico se definió como los valores y valoraciones que transmite la publicidad exterior. El objetivo de la definición del campo semántico era identificar por parte de los investigadores, lo que los sujetos exteriorizaron frente a la relación que existía entre ellos y las piezas publicitarias que se mostraron. Una vez definido el campo semántico, se procedió a definir las categorías de análisis. En cada grupo de discusión, el moderador de la sesión presentó varias piezas publicitarias en turnos correspondientes a las categorías de mercado encontradas; luego, a cada integrante del grupo se le entregó una hoja con un cuestionario de seis preguntas que debían responder de acuerdo con la imagen que habían seleccionado de manera individual. Estas mismas fueron la base para la discusión grupal.

Las categorías de análisis para los grupos de discusión fueron: Impacto de la pieza publicitaria en el sujeto, Aspectos sociales o culturales del entorno del sujeto que identifica en la pieza, Asociaciones que hace el sujeto entre su vida y la pieza publicitaria mostrada, Interés del sujeto por adquirir el bien/servicio/mensaje que anuncia la pieza.

\section{Sistematización de la información}

Una vez se realizaron los grupos de discusión, se hizo una sistematización de lo expresado por los participantes, tanto de manera escrita en los cuestionarios individuales, como en el discurso oral de la sesión grupal. Para el procesamiento de datos se utilizaron los programas Excel y Word de Microsoft para sistematizar la información recogida en el ejercicio de los grupos de discusión. La transcripción de la sesión de discusión se hizo a partir del concepto de insigth, es decir, los momentos en que la discusión producía situaciones de auto-reconocimiento entre los participantes. Las transcipciones de cuestionarios individuales y discusión grupal se leyeron y se etiquetaron buscando los consensos (Chávez, 2007), es decir, los acuerdos a los que el grupo llegó durante la dis- 
cusión. El programa Cmaptools se usó para hacer el mapeo de dichos consensos en cada una de las categorías analizadas. Los mapas se elaboraron a partir de las respuestas que dieron los participantes contadas por frecuencias de aparición en las sesiones. A partir de allí, se identificaron los ejes de valoración, es decir, los puntos desde los cuales se realizaban los juicios de valor por parte de los participantes.

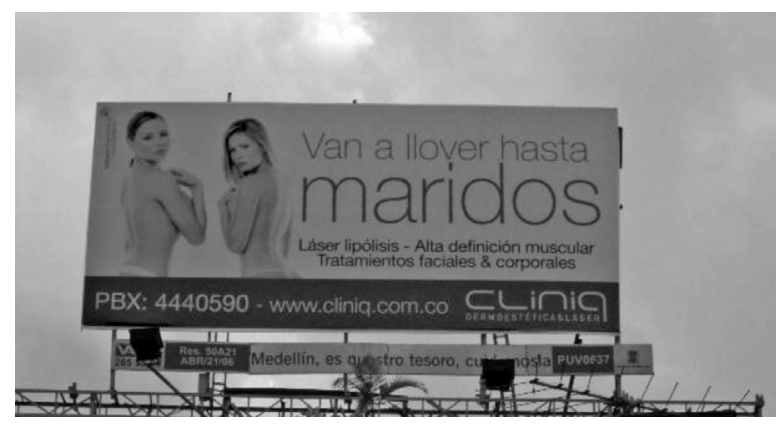

Valla ubicada en la calle 10

\section{RESULTADOS}

A continuación se presenta un análisis por categorías. El objetivo de presentar la información así es ayudar a descubrir la lógica propia de relación de los valores culturales con cada una de las categorías de bienes analizadas en el proyecto.

\section{Cuerpo}

En la categoría cuerpo, el 60\% de los participantes eligió las piezas de la clínica de cirugía plástica. Los entrevistados identificaron la belleza fabricada en el quirófano con el sexo femenino, y afirman que este tipo de belleza se construye por presión social, por obedecer a estereotipos impuestos por el entorno y por la publicidad. Ni la discusión realizada en grupo ni los cuestionarios diligenciados por cada entrevistado señalan la intervención quirúrgica en relación con lo masculino: la necesidad de intervenir el propio cuerpo para ser aceptado por los demás aparece como un asunto de las mujeres, y por eso la cirugía es vista como algo negativo: intervenirse es negarse a sí mismo. De aquí que la valoración se mueve en el eje auténtico e inauténtico, donde no importa si hay intervención quirúrgica o no, siempre que se siga siendo "uno mismo". Para los entrevistados, cuando se deja de ser uno mismo, se deja de ser auténtico por imitar los estereotipos de belleza impuestos por los medios y la publicidad.

Otro de los ejes de valoración que evidenciaron los sujetos en relación con esta categoría es la diferenciación entre la mujer que muestra demasiado su cuerpo ("mostrona") y la que lo muestra poco. Este eje imaginario presenta, en un lado, a una mujer exhibicionista que siempre está buscando atraer la atención del otro, por lo cual es catalogada como una mujer "fácil" (entendida como aquella que accede a los deseos sexuales del otro de manera ligera); por el otro, la mujer que muestra poco, una mujer más discreta en su relación con los otros desde su sexualidad.

\section{Vestuario}

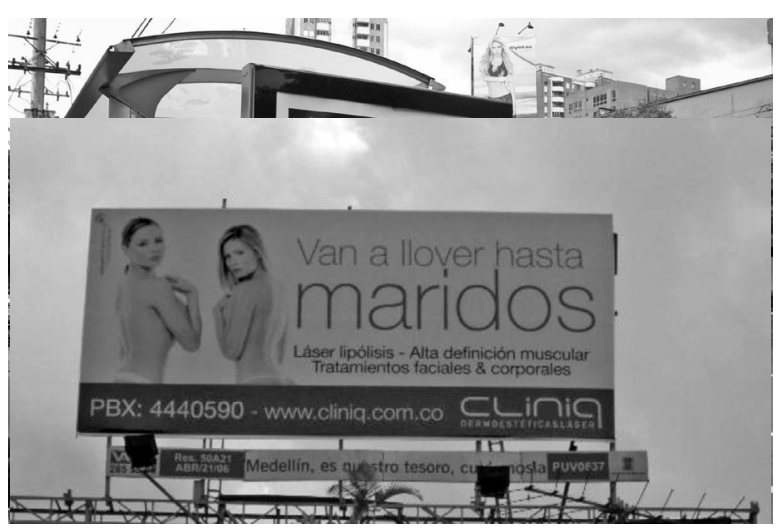

VaPieza publicitaria ubicada en la Av. El Poblado

Para la categoría vestuario, el 60\% de los participantes eligió dos piezas de la marca Diesel.

En esta categoría se repite que la moda -al igual que las cirugías plásticas- es un asunto femenino (a los hombres no compete tan urgentemente 
el deseo de verse y vestirse bien). El eje de valoración que se identifica aquí es lo estético, donde el extremo negativo es lo ordinario y el positivo es lo excéntrico. Lo ordinario entendido como la prenda barata que usa la gente del común, mientras que lo excéntrico está entendido como lo exclusivo, es decir, ropa que usan los jóvenes de estratos altos y cuya actitud frente a la prenda -o el cómo la luce- es catalogada por los participantes de la discusión como irreverente, descomplicada. Estas valoraciones se hacen para la marca de ropa Diesel, cuyas prendas son costosas y que se asocia a jóvenes con alto poder adquisitivo, y que para la época del trabajo de campo de esta investigación era promocionada con piezas publicitarias que rompían códigos de comportamiento social ${ }^{3}$. La relación masculino-femenino que connota el mensaje de Diesel contradice lo que se observa en las piezas publicitarias de las otras marcas de ropa que se anunciaban en el sector: mientras que Diesel muestra una mujer independiente, en las otras marcas de ropa la mujer se muestra para provocar el deseo masculino; de estas últimas se infiere, por lo tanto, que la mujer no está completa hasta que no tenga a su lado la figura masculina.

Otro eje de valoración que se evidencia en los cuestionarios y en las discusiones de los sujetos abordados en esta investigación es el proyecto de vida que pueden tener las mujeres que usan las marcas de ropa analizadas. Mientras que quienes utilizan la marca Diesel, no proyectan -con sus actitudes- el deseo de provocar al hombre, sino una actitud irreverente, desinhibida, las mujeres de las otras marcas (NY, Joystaz y Fiara) tienen una actitud abiertamente incitadora del deseo masculino. La ausencia de la figura masculina en las piezas elegidas por los sujetos sugiere la necesidad de esta figura en la vida de la mujer, por lo tanto, este esquema se aproxima más a

3 En una de las vallas, se observa a un joven que muerde las nalgas de una mujer. La campaña Be stupid de Diesel, apunta a olvidar los cánones sociales, a ser menos consciente, menos civilizado; a liberarse pero no con una actitud propositiva, política, sino de estupidización. las formas de estructuración tradicional de la familia (hombre-mujer). La independencia de la mujer representada en Diesel sugiere un proyecto independiente, mientras que el de las mujeres de las demás marcas se evidencia como un proyecto de vida en pareja.

\section{Bebidas}

En la categoría bebidas hubo menos consenso en cuanto a la marca, pero no a la bebida. De tal forma, el 15\% eligió la marca de cerveza Pilsen, otro 15\% eligió la marca de cerveza Águila, otro 15\% eligió la marca de cerveza Club Colombia y otro 15\% escogió la marca de cerveza Redd's; pero el 75\% de los participantes eligió las piezas que tenían publicidad de cerveza y dejó de lado aquellas que contenían publicidad de aguardiente o bebidas gaseosas. Así, bebida es sinónimo de encuentro para los jóvenes participantes en los grupos de discusión; un elemento que está presente en el ámbito social, familiar y de ocio en ellos. Por lo tanto, bebida es sinónimo de encuentro.

Los extremos del eje de valoración de las categorías son: fino y barato, formal e informal. Para el primer caso, el extremo barato está con la cerveza Pilsen y el extremo caro está asociado con el güisqui; en el segundo eje, el extremo informal es reunión con amigos, compañeros de estudios y trabajo; mientras que el extremo formal está asociado con la familia. Según esto, la bebida de encuentro con amigos y compañeros de estudio y/o trabajo es la cerveza, generalmente en reuniones informales, mientras que el aguardiente es la bebida que acompaña los momentos familiares, cuya connotación es básicamente formal, es decir, rituales con mayor codificación social como pri meras comuniones, matrimonios y graduaciones.

Otro eje de valoración encontrado está ligado a consumo por sexo donde el consumo del sexo masculino puede ser positivo o negativo y cuya escala está con la cantidad de licor que se ingiere: 
si es mucho o muy frecuente en el tiempo, es catalogado como negativo, pero si es esporádico es positivo. Opuesto a ello, el consumo femenino de bebidas siempre tiene connotaciones negativas, pues "una mujer borracha se ve muy fea" (sesión de grupo 2 mayo 14 de 2011).

\section{CONCLUSIONES}

Por lo que se pudo observar en los grupos de discusión realizados, así como en los cuestionarios que los participantes diligenciaron, los jóvenes son muy expresivos para abordar el tema de la publicidad y la relación de esta con su vida, cuando se trata de juzgar a los otros; sin embargo, su discurso se ve matizado cuando el análisis toca valores con los cuales cada uno de ellos se identifica; de tal manera que juzgan los comportamientos que van en contra de valores tan tradicionales como la familia, los amigos y el aprecio a la mujer, desde la otredad: cuando alguno de los participantes en el grupo de discusión o alguna de las piezas amenazaba con violentar alguna de esas creencias a través de las valoraciones que promovía, aparecían expresiones de rechazo en su contra. Frases como "Ciertas personas que conozco" fueron utilizadas por los participantes de los grupos de discusión para hacer referencia a personas con comportamientos censurables desde lo que ellos piensan. Al ver los ejes de valoración desde los cuales se construyeron los juicios personales y colectivos de los participantes, se evidencia que la marca proyecta o restringe los valores centrales de cada individuo, es decir, aquellos que se estructuran en la familia y que son reforzados en la escuela y en la iglesia (Kotler 2008). Esta identificación se evidencia en las valoraciones que tienen que ver con la inclusión y la exclusión de comportamientos y actitudes que asumen los otros en las piezas publicitarias sometidas a discusión.

Sin embargo, esta apreciación opera de maneras distintas según la categoría de producto analizada. Las categorías que arrojaron mayores datos frente a cómo la publicidad afecta la apropiación de los valores fueron las de vestuario y cuerpo, porque en esas piezas la mujer es utilizada como objeto de la marca. La utilización fetichista del cuerpo femenino violenta la alta valoración de la mujer en la cultura paisa ${ }^{1}$. Esta valoración se evidencia con mayor fuerza en el discurso hablado, particularmente por las mujeres participantes en los grupos de discusión, quienes afirmaron que para salir los fines de semana a compartir con amigos hay que ser "bonita y operada". Algunas de ellas afirmaron que las dos condicionen anteriores garantizan de alguna manera, conseguir un traqueto, término utilizado en esta zona del país para referirse a un matón o persona que trafica con drogas ilegales (Henao y Castañeda, 2001) y que quienes lo conseguían "rumbiaban" normalmente en el barrio Colombia de Medellín, una zona altamente reconocida porque allí se ubican las discotecas más costosas de la ciudad.

Ninguno de los participantes que hizo este tipo de comentarios se involucró en ellos o -a lo sumo- admitió que conocía a alguien "operada y con novio traqueto", pues estos comportamiento son censurados por ellos mismos como algo propio de mujeres grillas, término que si bien Henao, J. y Castañeda, L. (2001) registran como sinónimo de prostituta, es utilizado por los jóvenes en un sentido más amplio para referirse a mujeres provocadoras y ofrecidas, y cuya indumentaria es el principal signo de su condición: ropa escotada y con pedrería, normalmente con una o varias cirugías estéticas y una actitud abierta frente a su sexualidad.

La marca moviliza las valoraciones de los jóvenes, estableciendo unos ejes que unen las posiciones extremas -positiva y negativa- desde los cuales se establecen los juicios de valor. En lo referente a la marca de ropa, hay una diferencia muy relevante en cómo se mira a quien la lleva. Quien lleva ropa de marca Diesel es visto como una persona que rompe los esquemas de comportamiento que dicta la sociedad, pero esto no es juzgado como negativo. En claro contraste, a las mujeres que usan otro tipo de marcas de ropa 
(tanto modelos de las piezas publicitarias como personas en la cotidianidad) los participantes de los grupos de discusión las juzgan como grilla ${ }^{4}$.

Hay una base moral traducida en las palabras de quien interpreta esos mensajes; esa base moral es la que permite justificar el juicio que cada uno emite frente al mensaje. Allí vuelve a aparecer la otredad cuando se trata de descifrar el mensaje en clave negativa. Es el otro el que está equivocado al usar una marca o identificarse con un producto; en cambio, si la interpretación es positiva, el sujeto involucra la primera persona en su discurso, habla de "yo" o "nosotros" implícita o explícitamente. En el tema del vestuario, no es la desnudez realmente lo que se censura, es la actitud que transmite la modelo a los receptores de esa publicidad. Así se puedo comprobar con las piezas elegidas por los participantes de los grupos de discusión en la categoría vestuario, donde la modelo de la marca Diesel muestra más piel que las modelos de marcas como NYE, Fiara y Joytaz; sin embargo, Diesel generó valoraciones menos negativas que las otras piezas.

Pero mientras algunas marcas generan una opinión negativa, Diesel logró revertir codificaciones sociales pues validó y resignificó como comportamientos "frescos, chéveres, deseables", actitudes que están habitualmente fuera de lo admitido socialmente. En oposición, las otras marcas se tildan de mañé, término utilizado por los participantes en los grupos de discusión para referirse a ropa fea (Henao y Castañeda, 2001) las cuales están representadas por mujeres que intentan seducir hombres. Esto permite inferir que las valoraciones no están referidas a la materialidad del producto sino a los atributos de la marca (Sanín, 2008).

4 Si bien ni en las preguntas ni en las piezas publicitarias, se hizo alusión alguna a la palabra grilla, ésta surgió de manera inmediata y espontánea para analizar las usuarias de algunas marcas de ropa o las clínicas de cirugía estética que prometen belleza y cambios inmediatos en la apariencia femenina.
En la categoría cuerpo, los participantes de los grupos de discusión aseguran que quienes se hacen una cirugía son vacíos, superfluos, inseguros y moldeables a las exigencias del mundo exterior; la intervención en el cuerpo es tomada entonces como el reflejo de las presiones de una sociedad donde el canon de belleza pasa por ser delgados y remodelados en el quirófano. El juicio moral de los sujetos del grupo de discusión salta aquí, en cuanto a que estos señalan que quien se hace una cirugía no sopesa las consecuencias "malas" que esta le traerá; en oposición, muchos de los jóvenes afirmaron que es preferible ser natural, feíto, gordito. Allí se evidencia más la presencia de un valor que de una valoración, ese valor que desde lo religioso habla de que el cuerpo es sagrado y la vanidad es uno de los 7 pecados capitales. En este juicio moral impera el deber ser, el no dejarse presionar por la sociedad, por los estereotipos que la publicidad impone.

En esta categoría, cuerpo, los entrevistados evidencian la otredad cuando afirman que la belleza artificial es un asunto de los demás y lo miran desde la perspectiva del otro, se convierten en jueces de quienes se intervienen el cuerpo; lo califican como algo que trae consecuencias negativas. Por el contrario, en la categoría de bebidas ellos se involucran totalmente con el producto y las prácticas a las que está asociado, como ejemplo reuniones familiares o de amigos.

En cuanto a la categoría bebidas, se evidenció que la bebida está asociada con amigos y familia: se toma una cerveza para descansar y relajarse con los amigos; para compartir en familia es más usual el aguardiente. La amistad y la fraternidad familiar son valores fundamentales para los jóvenes de Medellín. De allí se puede inferir que, en general, el producto publicitado dialoga con lo que la gente cree sobre sus relaciones y valoraciones acerca de estos dos temas. Los valores centrales que traen los jóvenes desde su casa, y que se refuerzan en instituciones (MacIntyre, 2001) como la iglesia y la escuela, marcan el eje a través del cual 
ellos se apropiaron de los mensajes publicitarios a los que se vieron expuestos durante la época de la presente investigación, de tal forma que se puede leer claramente en el discurso de estos jóvenes cuáles son los valores más importantes para ellos con relación a la forma como asumen las marcas identificadas en cada una de las categorías. El siguiente gráfico ilustra la correlación que se identifica entre categorías de producto y la identificación de valores.

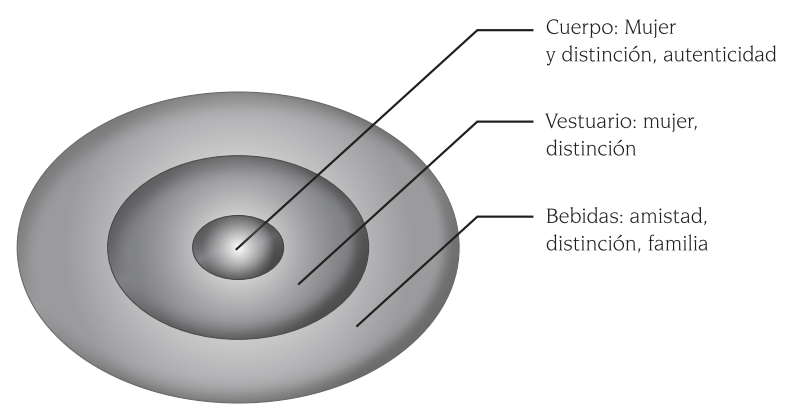

Fuente: elaboración propia

\section{Valores identificados en cada categoría. Valores identificados en la publicidad exterior analizada en la categoría cuerpo}

En esta categoría los valores más representativos son la autenticidad, la mujer y la distinción. Dado que en esta cultura la mujer en su rol social y familiar es alta y positivamente valorada, consideramos que esa valoración de la mujer es la que lleva a un rechazo de aquellas piezas publicitarias en las que ella aparece como incitadora del deseo masculino. La autenticidad está relacionada con la decisión de la mujer de asumirse o no como objeto de deseo para el hombre, en la medida en que las cirugías plásticas a través de las cuales se interviene el cuerpo ratifican esa condición de ser en busca de aprobación por parte del otro.

Si bien el valor familiar invita a la configuración de parejas, la forma en que la mujer la propicia -a través de la intervención quirúrgica de su cuerpo no es valorada positivamente en esta sociedad; por lo tanto, ese tipo de mujer es señalada como grilla.

\section{Valores identificados en la publicidad exterior analizada en la categoría vestuario}

En esta categoría los valores movilizados en la publicidad fueron distinción y mujer. La distinción opera como una estrategia de diferenciación respecto a las mujeres que usan marcas de ropa como Joytaz y NYE y las que usan Diesel. Bajo la búsqueda de la distinción las primeras fueron calificadas como "ofrecidas y fáciles". En este sentido el vestuario surge como una proyección del cuerpo: las piezas publicitarias analizadas en las que aparecían mujeres usando prendas que dejaban mucha piel al descubierto, pero con actitud indiferente al receptor del mensaje, fueron percibidas de una manera positiva sin ningún juicio de valor frente a la prenda o el mensaje (piezas de Diesel), en contraposición con las modelos que aunque están más cubiertas intentan involucrar al receptor con su mirada directa y provocadora. Al igual que en la categoría cuerpo, el papel que asume la mujer en las piezas analizadas -como incitadora del deseo masculino- es lo que lleva al rechazo y señalamiento negativo de quienes usan las piezas, pues degradan la imagen de la mujer en la cultura paisa.

\section{Valores identificados en la publicidad exterior analizada en la categoría bebidas}

En la categoría bebidas los valores movilizados fueron amistad, distinción y familia. Las bebidas alcohólicas se asumen como un vehículo de encuentro con las personas más cercanas emo cionalmente entre quienes analizaron las piezas de esta investigación; la familia, seguida de los amigos, es el referente emocional más importante cuando se trata de relajarse y hacer una pausa en la cotidianidad. La bebida está asociada al diálogo, que es un factor de consolidación de la familia y la amistad. Por su parte, la distinción opera como la asociación del estatus que da la bebida a quien la 
consume, así como la identificación de esta con la amistad, ya que el producto está relacionado por los usuarios con los amigos.

Como ya se mencionó anteriormente, familia y amistad son valores fundamentales para los jóvenes de esta región del país. En la medida en que las piezas de la categoría bebida apelan a estos valores, la apropiación que se hace de estos mensajes es altamente positiva.

Considerando los argumentos anteriormente expuestos, se puede afirmar como conclusión general y en respuesta a la pregunta de investigación planteada, que la estructura de valores culturales en los jóvenes no se ve afectada por la publicidad, sino que, por el contrario, se constituye en el referente desde el cual esta se interpreta.

\section{Referencias bibliográficas}

Alcaldía de Medellín. Medellín portal de la ciudad. Tomado de: http://www.medellin.gov.co/irj/portal/vis itantes?NavigationTarget $=$ navurl://ff556ed54f8f4fb94e0c28e0bb15d9c8. Fecha de consulta noviembre 25 de 2011

Aprile, O. (2000). La publicidad estratégica. Paidós, Argentina.

Aristóteles (2004). Poética. Traducción Alicia Villar Lecumberri. Alianza, Madrid.

Berganza, M. y García, M. (2005). El método científico aplicado a la investigación en Comunicación Mediática. En: Berganza, M E Ruiz, S. (2005). Coordinadores. Investigar en comunicación. Madrid: McGrawHill.

Bourdieu, P. (2010). El sentido social del gusto: elementos para una sociología de la cultura. Argentina: Siglo XXI.

Campbell, J. (1953). El héroe de las mil caras: Psicoanálisis del mito. México: FCE.

Chávez, M. G. (2007). El Grupo de discusión (Primera edición ed.). México: Universidad de Colima.
Cuartas, P. (2010). El rey está desnudo: Ensayos sobre la cultura de consumo en Medellín. Medellín: La Carreta Editores.

DANE. (2011, 13-09-2010). Boletín censo general 2005, Medellín Antioquia Retrieved Noviembre 23 de 2011, 2011. Tomado de http://www.dane.gov.co/files/censo2005/PERFIL PDF CG2005/05001T7T000.PDF

Eco, U. (1986). La estructura ausente. Introducción a la semiótica. Barcelona: Lumen.

García, N. (1995). Consumidores y ciudadanos: Conflictos multiculturales de la globalización. México: Grijalbo.

Girard, R. (2008). Anorexia y deseo mimético. L'Herne, Paris. Traducción inédita de Luis Alfonso Paláu, Medellín, 2009. Documento de trabajo.

Guía turística de Medellín. Esta es la Guía Turística oficial de Medellín, fue realizada por la Fundación Víztaz en alianza con la Alcaldía de Medellín, también se puede adquirir en multimedia y papel. Tomada de: http://www.guiaturisticademedellin.com/

Henao, J. y Castañeda, L. (Eds.) (2001). El parlache (primera edición ed.). Medellín: Editorial Universidad de Antioquia.

Kotler, P. y Armstrong, G. (2008). Principios de Marketing. 12 Edición. Madrid España: Pearson Editores.

MacIntyre, A. (2001). Tras la virtud. Barcelona: Crítica.

Marina, J. (2007). Las arquitecturas del deseo. Barcelona: Anagrama.

Martín-Barbero, J. (1995). Pre-textos: conversaciones sobre la comunicación y sus contextos. Cali: Universidad del Valle.

Montoya, J. (1964). Los valores y la teoría social. Revista Mexicana de Sociología. Vol. 26. N. ${ }^{\circ} 1$ (ene-abr), pp. 153-171.

Orozco, G. (2001). Televisión, audiencias y educación. Buenos Aires: Norma.

Pérez, A. y Londoño, I. (1997). Caracterización de los jóvenes de Medellín (Investigación de revisión bibliográfica). 
Fundación Social, Secretaría de Bienestar Social Corporación Paisajoven G.T.Z. Tomado de: http:// www.cinterfor.org.uy/public/spanish/region/ampro/ cinterfor/temas/youth/doc/not/libro217/libro217. pdf

Rincón, O. (1998). Políticas culturales de medios de comunicación. Televisión regional, local y educativa. En: Signo y pensamiento, N. ${ }^{\circ}$ 32. Universidad Javeriana, Bogotá. p. 41-60.
Sanín, J. (2008). Estéticas del consumo: configuraciones de la cultura material. Medellín: UPB 
